\title{
Spontaneous Isolated Iliopsoas Tendon Tear in Elderly-Case Report and Review of Literature
}

\author{
Ramanan Rajakulasingam ${ }^{1}$ Christine Azzopardi ${ }^{2}$ Peter Dutton ${ }^{3}$ David Beale ${ }^{4}$ Rajesh Botchu ${ }^{2}$
}

1 Department of Musculoskeletal Radiology, Royal National Orthopaedic Hospital, Stanmore, United Kingdom

2 Department of Musculoskeletal Radiology, Royal Orthopaedic Hospital NHS Foundation Trust, Birmingham, United Kingdom

${ }^{3}$ Church Hill Treatment Centre, Northfield, Birmignham, United Kingdom

${ }^{4}$ Heath Lodge Clinic, Knowle, United Kingdom

\begin{abstract}
Address for correspondence Rajesh Botchu, FRCR, Department of Musculoskeletal Radiology, The Royal Orthopedic Hospital, Bristol Road South, Northfield, Birmingham B31 2AP, United Kingdom (e-mail: drbrajesh@yahoo.com).
\end{abstract}

Indian J Radiol Imaging 2021;31:719-720.

\section{Abstract \\ Keywords \\ - iliopsoas \\ - rupture \\ - elderly}

Iliopsoas tendon tears are rare. These typically occur in young and can be associated with avulsion fractures of lesser trochanter. We report a case of full thickness rupture of iliopsoas tendon in 87-year-old male without avulsion of the lesser trochanter.

\section{Case Report}

An 87-year-old male presented with sudden onset of left groin and anterior thigh pain. There was no history of trauma. His past medical history was unremarkable. On examination, he had weakness of hip flexion but had full range of movements. There was no hematoma or bruising in the groin. MRI was organized to evaluate this further. MRI showed non visualization of the distal iliopsoas tendon (IPT) at its lesser trochanter insertion in keeping with full thickness rupture. The tendon fibers are retracted proximally with prominent fluid traversing the now empty tendon sheath. Despite some soft tissue edema surrounding the retracted IPT, no significant lesser trochanter bone marrow edema or avulsion was seen. The findings are therefore in keeping with a proximally retracted full thickness IPT rupture without bony avulsion (-Figs. 1, 2). He was managed nonoperatively with analgesia and physiotherapy.

\section{Discussion}

Iliopsoas injuries are rare, but typically occur due to athletic injury with tendon avulsion and lesser trochanter detachment. ${ }^{1}$ In the absence of trauma, trochanteric avulsion is always considered secondary to metastatic disease until proven otherwise. IPT tears without avulsion are very rare, but predisposing factors include metastases, chronic steroid use, and post hip arthroplasty. ${ }^{1}$ Interestingly, there a few case reports of spontaneous bilateral IPT tears without bony avulsion or any preceding trauma. ${ }^{1,2}$ Bui et al describes features of IPT tears in 32 patients. $^{3}$ The most common injury in patients under 65 years were muscle strains and partial tears, usually due to an athletic injury. However, in patients over 65 the most common injury was a complete tear, with most sustaining trauma from a fall, while two had a spontaneous origin. It is speculated that gender hormonal differences may partially account for the elderly female predilection of such tears. ${ }^{3}$
DOI https://doi.org/ 10.1055/s-0041-1735499. ISSN 0971-3026. (c) 2021. Indian Radiological Association. All rights reserved.

This is an open access article published by Thieme under the terms of the Creative Commons Attribution-NonDerivative-NonCommercial-License, permitting copying and reproduction so long as the original work is given appropriate credit. Contents may not be used for commercial purposes, or adapted, remixed, transformed or built upon. (https://creativecommons.org/ licenses/by-nc-nd/4.0/)

Thieme Medical and Scientific Publishers Pvt. Ltd., A-12, 2nd Floor, Sector 2, Noida-201301 UP, India 


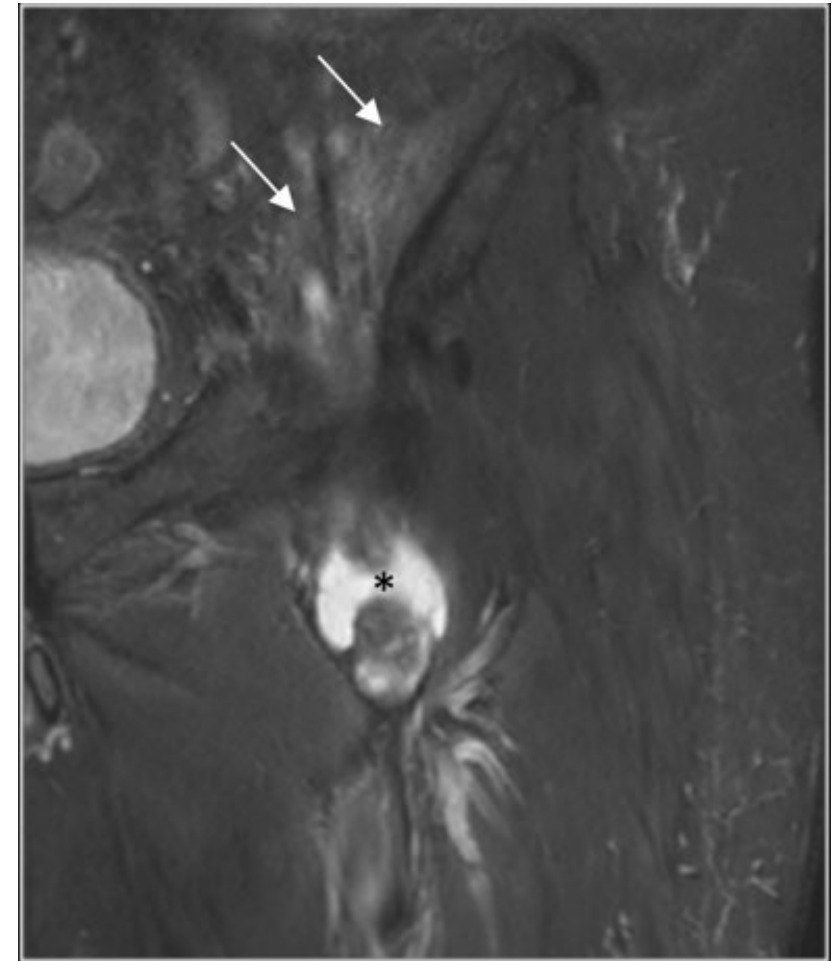

Fig. 1 Coronal PD FS image of the left pelvis showing high signal in the proximal portions of the iliacus and psoas muscles (arrows). Additionally, there is full thickness rupture and retraction of the psoas tendon with surrounding hematoma formation $\left({ }^{*}\right)$. FS, fat saturated; PD, proton density.

The MRI appearances in our case are very similar to the only published series of two patients specifically analyzing distal IPT tears without avulsion by Lecouvet et al. ${ }^{4}$ Proximally, there is some high signal intensity of the IP muscle (-Fig. 1). Inferiorly, the more medial psoas tendinous component is completely torn, thickened, and retracted ( - Fig. 2a,b) with prominent sheath fluid. There is, however, some preservation of the more lateral iliacus muscle, with some visible insertional fibers (-Fig. $\mathbf{2 c , d}$ ). The distal psoas tendon (made up of psoas and medial iliacus muscle fibers) has a purely tendinous insertion, but the more lateral, distal fibers of iliacus remain muscular until its anterior surface insertion. ${ }^{5}$ The latter is therefore possibly more resistant to complete tearing unlike the psoas tendon and may have played a role in our patient's recovery.

IPT tears present with severe groin pain, with a palpable mass representing bunching of the retracted tendon fibers. Patients typically complain of hip flexion pain against resistance. MRI remains the best imaging modality to identify the tendon tear and evaluate osseous structures. It allows accurate delineation of the rupture, enabling differentiation from tumors or bursae in the region.

Our patient was treated with physiotherapy alone. There are no reported cases of surgical management in this specific cohort. This case highlights that the most severe IPT injury-a complete tear, is more a function of age and gender rather than athletic injury or severe trauma. The diagnosis should

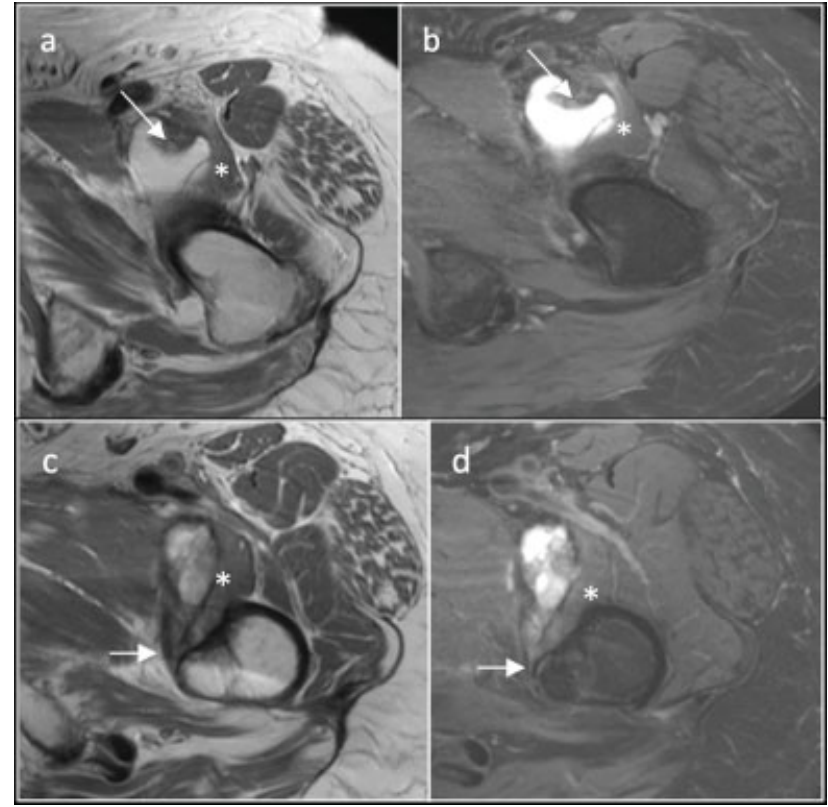

Fig. 2 Panels (a) and (b) at the level of the adductor musculature show a thickened and retracted psoas tendon with prominent surrounding fluid (arrows). Distally in (c) and (d) there is an otherwise empty fluid-filled psoas tendon sheath tracking to the lesser trochanter insertion (arrows). Note the persistence of more lateral muscles fibers in (a) to (d), indicating a partially intact distal insertion of the lateral iliacus muscle fibers onto the lesser trochanter $\left(^{*}\right)$.

therefore be considered in an elderly patient presenting with acute groin pain exacerbated by hip flexion/extension and normal radiographs.

\section{Conclusion}

IPT tears without avulsion fracture of the lesser trochanter are extremely rare in elderly and should be considered in the differential of groin pain.

Conflict of Interest

None declared.

\section{References}

1 Rubio M, Rodriguez M, Patnaik S, Wang P. Spontaneous iliopsoas tendon tear: a rare cause of hip pain in the elderly. Geriatr Orthop Surg Rehabil 2016;7(01):30-32

2 Algazwi DAR, Sia SY, Teng VSY, Hallinan JTPD. Spontaneous bilateral iliopsoas tendon tears. Am J Phys Med Rehabil 2019;98 (09):e112-e113

3 Bui KL, Ilaslan H, Recht M, Sundaram M. Iliopsoas injury: an MRI study of patterns and prevalence correlated with clinical findings. Skeletal Radiol 2008;37(03):245-249

4 Lecouvet FE, Demondion X, Leemrijse T, Vande Berg BC, Devogelaer JP, Malghem J. Spontaneous rupture of the distal iliopsoas tendon: clinical and imaging findings, with anatomic correlations. Eur Radiol 2005;15(11):2341-2346

5 Tatu L, Parratte B, Vuillier F, Diop M, Monnier G. Descriptive anatomy of the femoral portion of the iliopsoas muscle. Anatomical basis of anterior snapping of the hip. Surg Radiol Anat 2001;23 (06):371-374 